and in particular whether the balance of activity and initiative in nuclear development between the Central Electricity Generating Board and the Atomic Energy Authority is correct. Here again questions of Government structure may also arise, particularly in respect of the position of the Ministry of Technology.

Other questions suggested for consideration in the Broadsheet are the structural division of electricity supply for England and Wales and for Scotland, and whether there is scope for forms of combined technical development between the industries, and possibly coal or oil also, that are being ignored at present because of the structural separation and competition. The Broadsheet also questions whether limits should be put to commercially competitive promotion between the nationalized fuel industries, and how far they should be obliged to keep their investment policies with the Government's forecasts of solid and other smokeless fuel requirements arisirg from application of the Clean Air Policy. The principles to be followed in permitting these nationalized industries to diversify their activities in the fields outside those in which they now operate also require definition. The Broadsheet hints plainly that the consumer is not at present adequately informed of the price trends in the various fuels. The present structure of the Ministry of Power also requires consideration in the context of how far it conduces to a sensible co-ordination of national energy policy and to objective assessments of conflicts of policy between the nationalized fuel industries.

It should also be remembered that some of the technological changes that could occur in the supply of energy would bring with them new questions about the structure of the British fuel industries. For example, if large-scale natural gas-fields were in fact found in the North Sea, the present gas industry, with its virtual monopoly and its commitment to manufacture gas at lower calorific values, might not be the ideal instrument to introduce the natural gas into the British market. Possibly a measure of competition should be introduced when gas supply becomes more and more based on the end-products of oil refining. Nor should it be without due consideration whether the cconomies of scale in supply or in transmission are as compelling, or whether monopoly is as appropriate a form of organization for gas as for electricity supply. The Broadsheet offors no answers to these problems, but it does suggest that urgent public consideration should be given to them and particularly to the determination of the right order of priorities. This is especially so in regard to what protection the fuel industry should receive, particularly British coal, and in what form.

\title{
U.S. STANDARD FREQUENCY AND TIME SERVICES
}

\begin{abstract}
A REVISED (1965) publication of the United States National Bureau of Standards* gives a detailed and illustrated description of the services provided by the Standard Frequency Stations now operating in Washington, Hawaii and Colorado. The first is the well-known station, $W W V$, at Greenbelt, Maryland, which has been in operation since 1933, and now provides services of radio and audio frequencies, musical pitch, time signals and the departure of these from astronomical time; propagation forecasts and geophysical alerts are also issued from $W W V$. An additional service was started from Hawaii in 1948; but this is confined to radio frequencies, time signals and their corrections. In 1963, two low-frequency transmissions were added from stations at Fort Collits, Colorado. One, $W W V B$, broadcasts continuously on the standard frequency of $60 \mathrm{kc} / \mathrm{s}$, and provides time signals and corrections, while the other, $W W V L$, broadeasts continuously on the standard frequency of $20 \mathrm{kc} / \mathrm{s}$. The frequencies of all these services are held stable in general to a few parts in $10^{11}$, and they are ultimatoly referred to the resonance frequency of caesium, which is measured in terms of ephemeris time.

All the carrier and modulation frequencies at $W W V$ and $W W V H$ are derived from precision quartz oscillators of

* United States Department of Commeree: National Bureau of Standards. Miscellaneous Publication 236: Standard Frequencies and Time Services of the
National Bureau of Standards. Pp. 8. (Washington, D.C.: Government Printing Office, 1965.) 15 cents.
\end{abstract}

high stability. These are offset from the standard by a small but precisely known amount to reduce departure between the time signals as broadcast and astronomical time, U.T.2. Although the latter is subject to unpredictable changes readily noted at this level of precision, it is expected that the present offset-150 parts in $10^{10}$ established in 1964, will remain in effect for the present calendar year (1965). For the benefit of users who wish to make direct comparisons of absolute frequencies, $W W V B$ has been transmitting on $60 \mathrm{kc} / \mathrm{s}$ with no offset since January 1, 1965.

A comprehensive description, with diagrams, of all these services is given in the report, together with details of the propagation forecasts and geophysical alerts which are disseminatod at hourly intervals. The forecast announcement tells users, in a simple code form, the condition of the ionosphere at the regular time of issue, and the quality of radio services due to propagation conditions to be expected during the next $6 \mathrm{~h}$. A series of letter symbols is used to indicate the current geophysical conditions and give notice of any outstanding solar or geophysical ovents which are expected or which have occurred in the preceding $24 \mathrm{~h}$.

The revised issue of this publication will be welcomed by all users of frequencies and time signals, as well as by research workers in the fields of radio and the geophysical and solar sciencos.

R. L. SMith-ROSE

\section{COMMERCIAL NUCLEAR POWER STATIONS IN BRITAIN}

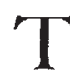

HE principal contents of the July number of the Journal of the British Nuclear Energy Society (4, No. 3; 1965) consists of the texts of the six papers contributed by members of the Central Electricity Generating Board and the South of Scotland Electricity Board and presented to the symposium on the performance of commercial nuclear power stations in the United Kingdom, which was held at the University of Leicester on June 30.

H. M. Carruthers, in his discussion of the evolution of magnox station design, points out that, in the nine years since the first Calder Hall reactor went critical, some thirty-five reactors of this basic type have been built, of which twenty-six are in Great Britain. The reactors during this period have developed from a small unit of about $40 \mathrm{MW}(\theta)$ output to one of nearly $600 \mathrm{MW}(\Theta)$ with at the same time reduced capital and generating costs. The main technical improvements in layout, shielding, refuelling methods, pressure circuit technology and fuel element design since the start of the commercial magnox programme are described in some detail.

The commissioning of a nuclear power station requires not only the setting of the plant to work safely and 